\title{
A study through batch tests on the analytical determination and the fate and removal of methamphetamine in the biological treatment of domestic wastewater
}

\author{
Maria Rosaria Boni ${ }^{1}$ - Agostina Chiavola ${ }^{1}$ - Camilla Di Marcantonio ${ }^{1}$ (D) $\cdot$ Silvia Sbaffoni $^{2} \cdot$ Stefano Biagioli $^{3}$. \\ Giancarlo Cecchini ${ }^{3} \cdot$ Alessandro Frugis $^{3}$
}

Received: 31 October 2017 / Accepted: 16 January 2018 / Published online: 29 January 2018

(C) Springer-Verlag GmbH Germany, part of Springer Nature 2018

\begin{abstract}
Methamphetamine (MET) is one of the most used illicit drugs in Europe and is recognized as one of the Emerging Organic Micropollutants. It is discharged into the sewerage system from different sources and then enters the wastewater treatment plants. The present study aimed at providing a better knowledge of the fate of MET through the wastewater treatment plants. The study addressed two different issues: (1) optimization of the analytical methods for MET determination in both liquid and sludge phases, focusing on the effects of potentially interfering substances and (2) investigation on the behaviour of MET in the biological treatment process, with specific concern for the biomass activity at different drug concentrations. Results of the study on issue 1 highlighted that the applied analytical method for MET determination (UPLC-MS/MS) is affected by the main components of wastewater for about 9-23\%, which is comparable with the uncertainties of the method (about $\pm 28 \%$ ). The method showed also to be repeatable and reliable (recovery $>75 \%$; repeatability $<10-15 \%$; bias uncertainty $<30 \%$ ), and relatively easy-to-use. Therefore, it can be considered suitable for measurements on routine base in the WWTPs. Batch tests conducted to address issue 2 showed total removal of 84,90 , and $96 \%$ at 50, 100, and $200 \mathrm{ng} / \mathrm{L}$ initial MET concentration, respectively, for a contact time of $6 \mathrm{~h}$. The removal process was mainly ascribed to the biological activity of both heterotrophic and autotrophic bacteria. The pseudo first-order kinetic model provided the best fitting of the experimental data of the overall biological processes at all the tested concentrations. Furthermore, the respirometric tests showed that MET does not induce any inhibition. Adsorption of MET on activated sludge was always very low.
\end{abstract}

Keywords Biodegradation $\cdot$ Emerging contaminants $\cdot$ Domestic wastewater $\cdot$ Illicit drugs $\cdot$ Methamphetamine $\cdot$ Respirometric test

Responsible editor: Ester Heath

Electronic supplementary material The online version of this article (https://doi.org/10.1007/s11356-018-1321-y) contains supplementary material, which is available to authorized users.

Camilla Di Marcantonio

camilla.dimarcantonio@uniroma1.it

1 Department of Civil Building and Environmental Engineering (DICEA), Sapienza University of Rome, Via Eudossiana 18, Rome, Italy

2 ENEA-Italian National Agency for New Technologies, Energy and Sustainable Economic Development, Research Centre Casaccia, Technical Unit for Environmental Technologies, Via Anguillarese 301, 00123 Rome, Italy

3 ACEA ELABORI SpA, Via Vitorchiano 165, Rome, Italy

\section{Introduction}

Illicit drugs belong to the wide class of Emerging Organic Micropollutants (EOMs) which includes various recalcitrant inorganic and organic pollutants (Deblonde et al. 2011). The main illicit stimulant drugs used in Europe are cocaine, amphetamine, methamphetamine (MET), and 3,4methylenedioxymethamphetamine (MDMA) (European Monitoring Centre for Drugs and Drug Addiction 2017). Amphetamine and methamphetamine are closely related to synthetic stimulants, known as amphetamines. Amphetamine type stimulants are generally manufactured in clandestine laboratories because there are no commercial supplies available as well as a natural source. Commonly, clandestine laboratory wastes containing residual parent drugs, unreactive precursors and byproducts are disposed of in domestic garbage or discharged on 
soil or in toilet and then transferred to sewage. Similarly to other illicit drugs, MET is also released into the sewerage system through human excretion, as either parent compound or mixture of metabolites. Then, the sewage enters the wastewater treatment plants (WWTPs), with influent concentrations of MET in the range of 1-600 ng/L (Deblonde et al. 2011; Irvine et al. 2011; Baker and Kasprzyk-Hordern 2013). Conventional secondary processes (activated sludge) represent the most extensively used and studied systems for domestic sewage treatment. However, these processes have not been designed to address the presence of EOMs in the wastewater; some removal/ transformation of these compounds can also occur in the WWTPs, but its extent is still uncertain and dependent on a number of parameters and conditions. Due to this, the WWTPs are considered the main source of release of drugs and other EOMs into the environment through both liquid and solid effluents (Díaz-Cruz et al. 2009). Illicit drugs are considered potentially toxic and their impact is increasingly being recognized as a critical issue affecting the environment and human health (Pal et al. 2015). Few reports are available in the specialized literature about the fate of drugs in the WWTPs (Nefau et al. 2013; Boix et al. 2015; Bodík et al. 2016; Devault et al. 2016). These few studies indicate that drugs and their metabolites undergo a series of processes in the biological treatment such as volatilization, adsorption, biodegradation, depending on their chemical-physical properties, and the specific wastewater characteristics (Chiavola et al. 2017). Some drugs, such as MET, are reported to be partly biodegraded in the biological reactor; furthermore, they can be also found adsorbed onto sludge solids. The real capacity of these processes to reduce MET concentration in a WWTP for domestic sewage is still unknown (Andersen et al. 2005; Bagnall et al. 2012). Therefore, there is the need to improve the knowledge about the behaviour of drugs in the WWTPs and particularly the effects of the different operating parameters (e.g. the sludge retention time) on the removal efficiency. A better knowledge would allow to implement specific measures/operating conditions in the WWTPs capable of reducing the amount of these compounds released into the environment and, consequently the negative effects.

From the analytical point of view, wastewater and sewage sludge are complex matrices and contain a number of components, such as inorganic anions and heavy metals (Vilardi et al. 2017) and other organic compounds that are potential interferences in the determination of drugs (Castiglioni et al. 2016). Furthermore, wastewater and sludge composition in the WWTPs change with time and among the plants (Gerrity et al. 2011; Gómez et al. 2012). In order to obtain a better knowledge of the fate of drugs in the WWTPs it is of key importance to have an analytical determination method offering reliability and reproducibility no matter the wastewater and sludge composition can be. Furthermore, the method must be relatively easy-to-use so as to allow measurements on a routine base, to monitor removal/transformation within the different processes implemented in a WWTP. According to the specialized literature, liquid chromatography coupled with tandem mass spectrometry is the method of choice for the analysis of drugs of abuse in the aqueous environment due to the high signal to noise ratio and the selectivity offered (Baker and Kasprzyk-Hordern 2011; Castiglioni et al. 2014; Andrés-Costa et al. 2017). The purposes of this study are double: (1) optimization of the analytical method for MET determination in both liquid and sludge phases (recovery $>$ $75 \%$; repeatability $<10-15 \%$; bias uncertainty $<30 \%$ ), focusing on the effects of potentially interfering substances found in the domestic wastewater and (2) achievement of a better knowledge on the fate of MET in the biological treatment processes, with specific concern to the response of the biomass to different MET concentrations.

\section{Materials and methods}

\section{Chemicals}

Standard $( \pm)$-methamphetamine solution was purchased from Sigma-Aldrich Company (Gillingham, UK) at a concentration of $100 \mu \mathrm{g} / \mathrm{mL}$ in methanol. This solution was then diluted in methanol at $99 \%$ to achieve the fixed concentrations required for the batch tests. Main characteristics of MET are reported in Table 1, where $S$ stands for solubility in water and $H$ for the Henry's constant.

The activated sludge samples were collected at a full-scale WWTP for domestic sewage and stored at $4{ }^{\circ} \mathrm{C}$ until use. Biological batch tests were carried out providing the activated sludge with a solution containing both macro- and micronutrients needed for the metabolic activity. Particularly, nitrogen and phosphorous solutions were made by dissolving ammonium chloride $\left(\mathrm{NH}_{4} \mathrm{Cl}\right)$ and sodium dihydrogen phosphate $\left(\mathrm{NaH}_{2} \mathrm{PO}_{4}\right)$ into deionized water (MilliQ water), respectively. Micronutrient solution was made according to OECD n. 209 (OECD, 2010), i.e., by dissolving into $1 \mathrm{~L}$ deionized water the following components: $0.7 \mathrm{~g} \mathrm{NaCl}, 0.4 \mathrm{~g} \mathrm{CaCl}_{2} \cdot 2 \mathrm{H}_{2} \mathrm{O}$, and $0.2 \mathrm{~g} \mathrm{MgSO}_{4} \cdot 7 \mathrm{H}_{2} \mathrm{O}$. In some tests, nitrification was inhibited by using a solution of $\mathrm{N}$-allylthiourea in MilliQ water at a concentration of $5.8 \mathrm{~g} / \mathrm{L}$ (ATU) as inhibitor. Organic carbon substrate was supplied by the methanol solution at $99 \%$ $\left(\mathrm{CH}_{3} \mathrm{OH}\right)$. All the solutions were always kept stored at $4{ }^{\circ} \mathrm{C}$.

\section{Analytical method description}

APHA methods (APHA 2005) were used to determine concentrations of the following parameters: $\mathrm{COD}, \mathrm{NH}^{-}-\mathrm{N}$, $\mathrm{NO}^{-}{ }^{-} \mathrm{N}, \mathrm{NO}^{-}{ }^{-} \mathrm{N}, \mathrm{MLSS}$, and MLVSS. $\mathrm{pH}$, temperature and DO were measured using standard probes (Hanna Instruments). Quantitative analysis of the drug was performed 
Table 1 Main chemical-physical characteristics of MET

\begin{tabular}{|c|c|c|c|c|c|c|c|c|c|}
\hline & Structure & $\begin{array}{l}\text { IUPAC } \\
\text { nomenclature }\end{array}$ & $\begin{array}{l}\text { Molecular } \\
\text { weight }(\mathrm{g} / \mathrm{mol})\end{array}$ & Formula & $\log K_{\mathrm{OW}}$ & $\log K_{\mathrm{OC}}$ & $\mathrm{pK}_{\mathrm{a}}$ & $\begin{array}{l}\mathrm{H} \\
\left(\mathrm{atm} / \mathrm{m}^{3} \mathrm{~mol}\right)\end{array}$ & $\begin{array}{l}\mathrm{S} \\
(\mathrm{mg} / \mathrm{L})\end{array}$ \\
\hline MET & & $\begin{array}{l}\text { (2S)- } N \text {-methyl-1- } \\
\text { phenylpropan-2-amine }\end{array}$ & 149.24 & $\mathrm{C}_{10} \mathrm{H}_{15} \mathrm{~N}$ & 2.95 & 2.88 & 9.87 & $2.37 \times 10^{-6}$ & $1.33 \cdot 10^{4}$ \\
\hline
\end{tabular}

by means of Ultra-Performance Liquid Chromatography coupled to tandem Mass Spectrometry (UPLC-MS/MS). The UPLC was an Ultimate 3000 RS Thermo, equipped with two pumps, degasser, column oven compartment and auto sampler. The MS/MS was the type 5500 AB Sciex Q-Trap, equipped with Atlas Copco FS2 compressor, FX1 dryer, 2701 tank and nitrogen generator Zephyr Zero 16 LC-MS. The liquid sample preparation included only a filtration step by using a $0.2-\mu \mathrm{m}$ membrane filter of regenerated cellulose, followed by direct injection. This procedure makes the method more suitable for routine and rapid analysis.

The applied analyser and instrumental conditions were as follows:

-UPLC-MS/MS Chromatography column Phenomenex Kinetex $2.6 \mu \mathrm{m}$ Biphenyl 100A, $50 \times$ $2.1 \mathrm{~mm}$ with security-guard column at $30^{\circ} \mathrm{C}$. Mobile phase A: Milli-Q Reference A+ water with a chromatography column acidified with $0.1 \%$ formic acid; mobile phase B: LC-MS methanol acidified with $0.1 \%$ formic acid. The gradient elution conditions were from $95 \% \mathrm{~A}$ and $5 \% \mathrm{~B}$ to $0 \% \mathrm{~A}$ and $100 \% \mathrm{~B}$ in $10 \mathrm{~min}$. Flow was $0.4 \mathrm{~mL} / \mathrm{min}$. Each drug was quantified by Multiple Reaction Monitoring ratio (MRM) using the two most abundant precursor/product ion transitions.

-Analytical determination of drug concentration in the solid phase was carried out by following the Ultrasound assisted Extraction (USE) procedure, adding $10 \mathrm{~mL}$ of $50 \%$ methanol and $50 \%$ MilliQ water, for $15 \mathrm{~min}$ at room temperature. After this pre-treatment, the sample was filtered using a $0.2-\mu \mathrm{m}$ membrane filter and then injected as described above for the liquid phase. The recovery of the method was $>$ $75 \%$ (as reported in Table 2).

\section{Analytical method validation}

The expanded uncertainty of the method was calculated as described below for the two ion transitions:

$U_{\exp }=K \cdot \sqrt{S_{A}^{2}+S_{B}^{2}+S_{C}^{2}+S_{D}^{2}}$
The coverage factor (K) used was equal to 2 which gives a level of confidence of approximately $95 \%$ for $4^{\circ}$ of freedom.

The $4^{\circ}$ of freedom $\left(\mathrm{S}_{\mathrm{A}}^{2}, \mathrm{~S}_{\mathrm{B}}{ }^{2}, \mathrm{~S}_{\mathrm{C}}{ }^{2}, \mathrm{~S}_{\mathrm{D}}{ }^{2}\right)$ considered were as follows:

Repeatability: instrument precision. Average RSD\% was calculated on five replicates of three validation concentrations, of the respective integrated areas of the chromatographic peak.

Bias uncertainty: bias variability in different matrices. It was calculated as RSD\% on MET concentrations of four solutions defined in the following sections.

Accuracy: represents the calibration accuracy and was defined by the data processing software Multiquant as RSD\% of the experimental point of the calibration curves.

Pretreatment uncertainty: derived from the use of micropipettes as RSD \% on 10 measurements.

Determination of the limit of detection (LOD) and of quantification (LOQ) was done according to the following procedure: five times injection of a sample at a concentration close to the expected LOQ (i.e., $19 \mathrm{ng} / \mathrm{L}$ ), integration of analyte peaks, calculation of signal-to-noise ratios and their averages values, concentrations calculation, and definition of LOQ as the concentration that gives signal to noise ratio equal to 10 multiplication of LOD for a precautionary factor (equal to 2).

\section{Matrix effect tests}

A series of tests was carried out using four reference solutions containing the main components typically present in a domestic wastewater, i.e., ammonia, phosphorous, and micronutrients, and a fixed MET concentration. For instance, the solutions had the following compositions and were prepared according to the indications provided in the section "Chemicals":

Solution P: $50 \mathrm{ng} / \mathrm{L}$ MET, $25 \mathrm{mg} / \mathrm{L}$ P

Solution N: $50 \mathrm{ng} / \mathrm{L}$ MET, $60 \mathrm{mg} / \mathrm{L} \mathrm{NH}_{3}-\mathrm{N}$

Solution MN: $50 \mathrm{ng} / \mathrm{L}$ MET, micronutrients

Solution ATU: $50 \mathrm{ng} / \mathrm{L}$ MET, $23.2 \mathrm{mg} / \mathrm{L} N$-allylthiourea (ATU) 
Table 2 Validation parameters of the analytical method for MET detection (UPLC-MS/MS) in liquid and solid phases for the two ion transitions

\begin{tabular}{|c|c|c|c|c|c|c|c|c|c|c|c|c|}
\hline \multirow[t]{2}{*}{ Compound } & \multicolumn{3}{|c|}{$\begin{array}{l}\text { Concentration } \\
\text { used for method } \\
\text { validation }\end{array}$} & Repeatability & $\begin{array}{l}\text { Bias } \\
\text { uqncertainty }\end{array}$ & Linearity, $R^{2}$ & Accuracy & $\begin{array}{l}\text { Expanded } \\
\text { uncertainty }\end{array}$ & $\begin{array}{l}\text { LOD } \\
\text { liquid }\end{array}$ & $\begin{array}{l}\text { LOQ } \\
\text { liquid }\end{array}$ & $\begin{array}{l}\text { LOQ } \\
\text { solid }\end{array}$ & $\begin{array}{l}\text { Extraction recovery } \\
\text { from solid phase }\end{array}$ \\
\hline & (ng/ & & & $(\%)$ & $(\%)$ & $(\%)$ & $(\%)$ & $(\%)$ & (ng/L) & $(\mathrm{ng} / \mathrm{L})$ & (ng/gTSS) & $(\%)$ \\
\hline MET-1 & 19 & 105 & 429 & 2.7 & 21.9 & 0.9997 & 12.7 & 51 & 7.4 & 14.8 & 2.8 & $>75 \%$ \\
\hline$M E T-2$ & 19 & 105 & 429 & 3.3 & 13.3 & 0.9999 & -3.0 & 28 & 4.9 & 12.2 & 2.4 & $>75 \%$ \\
\hline
\end{tabular}

The effect of carbon compounds was not investigated since MET solutions are provided diluted in methanol, which is a carbon source.

Tests with Solution ATU were performed in order to check if the addition of ATU, used in some batch experiments described afterwards, and could also interfere the analytical determination of MET.

The matrix effect was evaluated by measuring MET concentration in each solution. Then, based on the comparison between the expected (as calculated) and the measured concentration, it was possible to determine if the detection of MET was compromised by the interaction with the other components of the tested solutions. From a statistical point of view this test coincides with Bias test. Its significance was also evaluated by the Fisher's exact test ( $F$ test): this is a partial test and it is appropriate for the determination of non-random associations between two categorical variables. For instance, the $F$ test allows to compare the variances of two data sets $\left(S_{\mathrm{A}}{ }^{2}\right.$ and $S_{\mathrm{B}}{ }^{2}$ ). The value of $F$ was calculated as reported below:

$F_{\text {calc }}=\frac{\sigma_{\mathrm{A}}^{2}}{\sigma_{\mathrm{B}}^{2}}$

where $\sigma_{\mathrm{A}}{ }^{2}$ is the variance of the difference between the detected concentration in each solutions and the expected one, whereas $\sigma_{\mathrm{B}}{ }^{2}$ stands for the repeatability of the analytical method.

The F calculated value was compared to the printout value for $\mathrm{n}-1, \mathrm{~m}-1$ degrees of freedom representing a significance level equal to $95 \%$ (Sokal and Rohlf 2009). In this case, $n$ and $\mathrm{m}$ were equal to 4 . The test is considered valid if:

$F_{\text {calc }} \leq F_{3,3}$

\section{Batch experiments}

This phase of the study aimed at investigating the contribution of biodegradation, adsorption onto sludge flocs and other abiotic processes in the removal of MET in the biological reactor of a WWTP. Furthermore, it was determined if increasing MET concentrations might determine any inhibition of the biomass activity in the activated sludge reactor.

The potential removal processes were studied using the same experimental setup as outlined in a previous work by
Chiavola et al. (2017). For instance, a series of batch tests was performed in a $600-\mathrm{mL}$ volume glass flask $(500 \mathrm{~mL}$ operating volume). Tests were repeated in duplicate, and the results obtained averaged. Each flask was placed on a jar tester to provide a mechanical stirring in order to maintain the content under completely mixed and aerated conditions; the flasks were covered with aluminium foils to avoid photodegradation phenomena while the temperature was maintained within the range $22 \pm 2{ }^{\circ} \mathrm{C}$. Through the addition of $\mathrm{NaOH} 30 \%(w / v)$, it was possible to maintain $\mathrm{pH}$ within 7.2-8.0, which is the range that ensures optimal conditions for nitrification.

The overall duration of each test was fixed at $24 \mathrm{~h}$ based on preliminary tests, with the aim to guarantee the achievement of equilibrium conditions. During the tests, drug concentration in the flasks was measured at fixed time intervals (i.e., 0, 3, 5, 6, and $24 \mathrm{~h}$ ) to determine kinetics of the removal process.

Nitrification and COD removal were also monitored, by analysing the following parameters at different sampling times: $\mathrm{COD}, \mathrm{NH}_{3}-\mathrm{N}, \mathrm{NO}_{2}-\mathrm{N}$, and $\mathrm{NO}_{3}-\mathrm{N}$, MLSS, and MLVSS concentrations. The sample volume at each contact time was equal to $20 \mathrm{~mL}$, considered enough for all the analytical determinations mentioned above. Sampling was carried out under stirring conditions, in order to collect each compound and phase in the same proportion. Furthermore, at the end of the experiment, the overall mass balance was calculated and no effect on the sample was confirmed.

MET concentration was also measured in the solid phase at the beginning and at the end of the tests.

The potential inhibition of MET on biomass activity was studied by using the same experimental setup and the type of batch tests as above described. The study was performed by following the Activated Sludge, Respiration Inhibition Test, Carbon and Ammonium Oxidation OECD 209 method (OECD 2010). This method, through the oxygen uptake rate (OUR) measurements, allows to determine how different concentrations of a test compound may affect microorganisms' activity. The specific oxygen uptake rate (SOUR) was also calculated, by normalizing the OUR to the MLSS content in the batch test, as reported below:

$\operatorname{SOUR}(\mathrm{t})=\frac{\mathrm{DO}_{0}-\mathrm{DO}(t)}{\Delta t \cdot \mathrm{MLSS}}$ 
where $\mathrm{DO}_{0}$ and $\mathrm{DO}(t)$ stand for the dissolved oxygen concentration measured at the beginning and at time $t$, respectively, of the test, while MLSS represents the average solid concentration. The test method indicates to measure SOUR at least after $3 \mathrm{~h}$ since the beginning; in the present study, SOUR was measured after $3 \mathrm{~h}$ and also $6 \mathrm{~h}$. Particularly, the flasks were continuously aerated for $3 \mathrm{~h}$; then, aeration was turned off and $\mathrm{DO}(t)$ was recorded every minute for a fixed time interval of $10 \mathrm{~min}$. The linear regression of $\mathrm{DO}(t)$ data allowed to determine the average OUR (and SOUR) within the interval of $10 \mathrm{~min}$. The linear fitting was considered acceptable when the correlation coefficient, $R^{2}$, was above 0.95 . The same procedure was repeated after $6 \mathrm{~h}$ since the beginning of the batch test.

The Respiration Inhibition Test allows to determine the value of ECx, which represents the concentration that reduces the oxygen uptake rate by $\mathrm{X}(\%)$. At the end of the test, the inhibition percentage is calculated by comparing the SOUR values measured in presence of the test compound (MET in the present case) and in absence (blank test).

The effect on carbon oxidising microorganisms only was also determined by measuring (according to the method) the SOUR after inhibition of nitrifiers bacteria through the addition of an inhibitor such as $N$-allylthiourea.

Three different initial concentrations of MET in the drugcontaminated solution were tested, i.e., 50,100 , and $200 \mathrm{ng} / \mathrm{L}$, which fall approximately within the range of values found in the influents to WWTPs in Europe (Deblonde et al. 2011; Irvine et al. 2011; Baker and Kasprzyk-Hordern 2013).

Five series of batch tests were carried out for each drug concentration. The series differed based on the type of mixed solution used in the batch, with the aim to evaluate contribution of each of the following processes to MET removal: (1) biodegradation by heterotrophic and autotrophic biomass, (2) biodegradation by heterotrophic biomass, (3) adsorption onto sludge flocs, and (4) other abiotic processes (e.g., ionization, hydrolysis, and volatilization).

Details of each series are reported below.

\section{Series A—overall biological process tests}

This test was accomplished with the aim to evaluate the overall biological process, i.e., involving both heterotrophic and autotrophic bacteria. The flasks were filled by a mixed solution containing a sample of activated sludge taken from the oxidation tank of a full-scale WWTP for domestic sewage, the drug-contaminated solution and micro- and macro-nutrients, in order to simulate the main components of the mixed liquor in the biological reactor of the WWTP. Prior to the addition of the drug-contaminated solution and other components, the sludge sample was maintained under completely mixed and aerated conditions for $24 \mathrm{~h}$ in order to bring the biomass into the endogenous respiration state. Tests were started (time $t=$ 0 ) when MET and other components were added to the flasks.

The initial concentrations inside the flasks were set as follows: $3000 \mathrm{mg} / \mathrm{L}$ MLSS, $300 \mathrm{mg} / \mathrm{L}$ COD (including methanol added through MET solution), $30 \mathrm{mg} / \mathrm{L} \mathrm{NH}_{3}-\mathrm{N}, 6 \mathrm{mg} / \mathrm{L} \mathrm{P}$, and $50 \mathrm{~mL}$ of micronutrients solution (according to OECD $\mathrm{n}$. 209).

\section{Series $A_{h e}$ - heterotrophic process tests}

The aim of this series of tests was to evaluate only the heterotrophic biomass activity in the presence of MET. The mixed solution was the same as in Series 1, except for the addition of $23.2 \mathrm{mg} / \mathrm{L} \mathrm{ATU}\left(10^{-4} \mathrm{~mol} / \mathrm{L}\right)$ in order to cause $100 \%$ inhibition of nitrifying activated sludge (ISO 8192).

\section{Series S-inactivated sludge tests}

This series of tests was performed with the aim to evaluate only adsorption of drugs onto sludge flocs. To this purpose, the test was carried out using inactivated sludge (by adding sodium azide $0.2 \% \mathrm{w} / \mathrm{v}$ ) and the drug-contaminated solution. Sludge inactivation was considered successful if DO concentration, monitored inside the flasks, never decreased throughout the duration of the test (Ying and Droste 2015).

\section{Series C-control tests}

Each flask was filled with drug solution and MilliQ water only, in order to evaluate contribution of abiotic processes such as ionization, hydrolysis, and volatilization.

\section{Series B-blank tests}

Blank tests were conducted under the same conditions as in Series A and Series $A_{h e}$ as described above and without MET addition. This type of test was performed with the aim to compare the biomass activity in the presence and absence of MET.

\section{Calculation methods}

\section{Removal processes}

Drug removal percentage in each series of batch tests was calculated based on the following equation:

Removal $(\%)=\frac{C_{0}-C_{\mathrm{e}}}{C_{0}} \cdot 100$

where $C_{0}$ and $C_{\mathrm{e}}$ represent drug concentration at the beginning and at the equilibrium time of the batch test, respectively. 


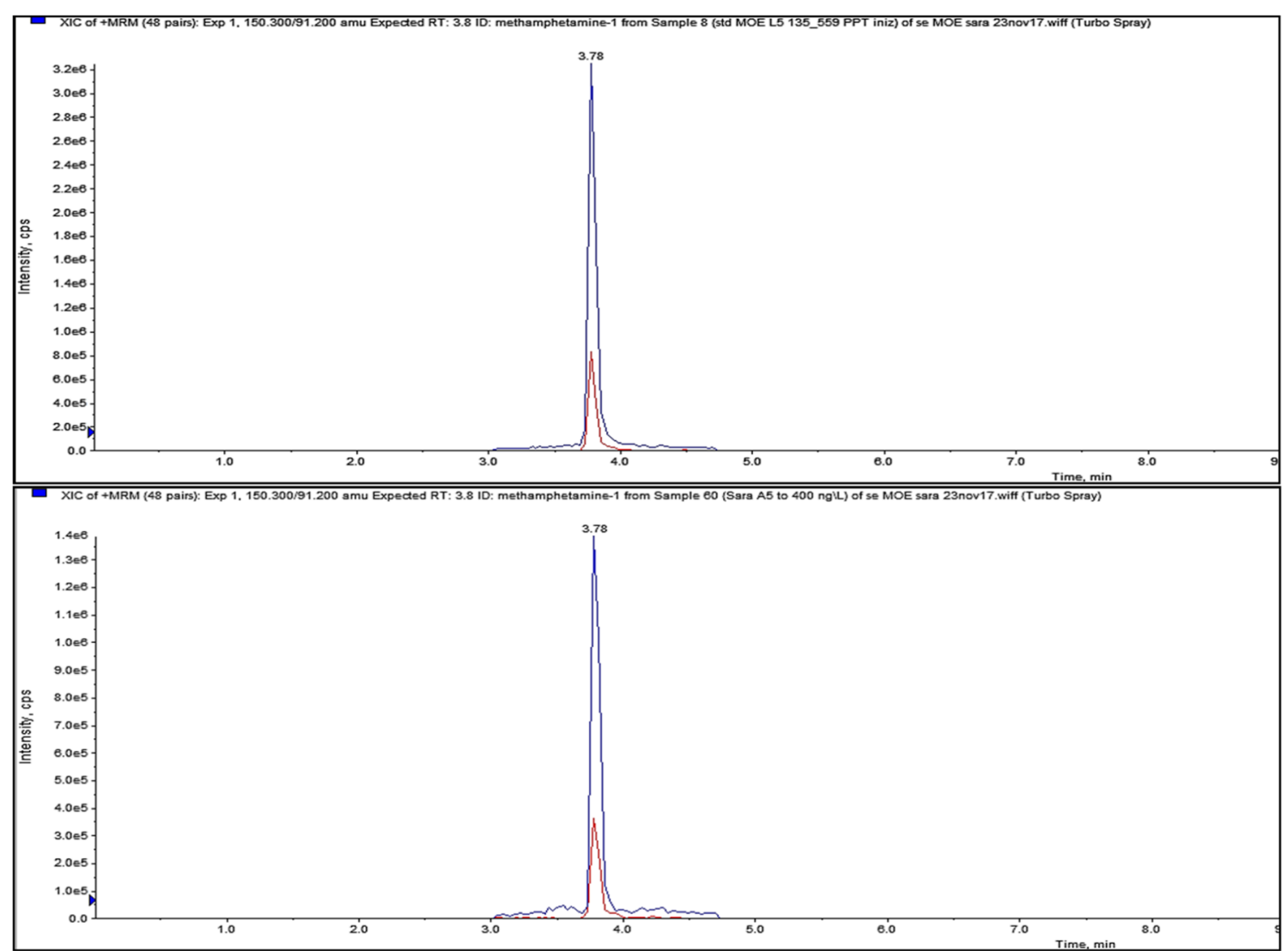

Fig. 1 Chromatograms related to $\mathbf{a}$ a standard solution and $\mathbf{b}$ a sample collected from one of the overall biological process tests

In Series $\mathrm{A}$ and Series $\mathrm{A}_{\mathrm{he}}$, all the processes, i.e., abiotic and biodegradation, were likely to take place. In Series S, all abiotic processes were reasonable to occur, while biodegradation was absent since activated sludge was maintained chemically inhibited. In Series C, the removal was assumed to be only due to abiotic processes.

Indicating with $\mathrm{RB}_{\mathrm{T}}, \mathrm{RB}_{\mathrm{he}}, \mathrm{RA}$, and $\mathrm{RO}$ percentage removal due to either only biodegradation, heterotrophic biodegradation (i.e., under inhibited nitrification), adsorption, and other abiotic processes, respectively, total removal in the four tests was assumed to be equal to:

$A(\%)=\mathrm{RBT}+\mathrm{RA}+\mathrm{RO}$

Ahe $(\%)=\mathrm{RBhe}+\mathrm{RA}+\mathrm{RO}$

$S(\%)=\mathrm{RA}+\mathrm{RO}$
$C(\%)=\mathrm{RO}$

where $A(\%), A_{\text {he }}(\%), S(\%)$, and $C(\%)$ stand for the total percentage removal measured in Series A, $A_{\text {he }}, S$ and $C$, respectively.

\section{Inhibition of biomass activity}

The effect on biomass activity of each tested concentration was expressed as percentage inhibition and calculated as described in OECD n.209 for the total oxygen consumption $\left(I_{\mathrm{T}} \%\right)$, the heterotrophic oxygen consumption $\left(I_{\mathrm{he}} \%\right)$, and the oxygen consumption due to nitrification $\left(I_{\mathrm{N}} \%\right)$ :

$I \mathrm{~T} \%=[1-($ SOURT $/$ SOURTB $] \cdot 100 \%$
Fig. 2 Relative error of matrix effect tests compared with expanded uncertainty $\left(U_{\mathrm{EXP}}\right)$ of the analytical method

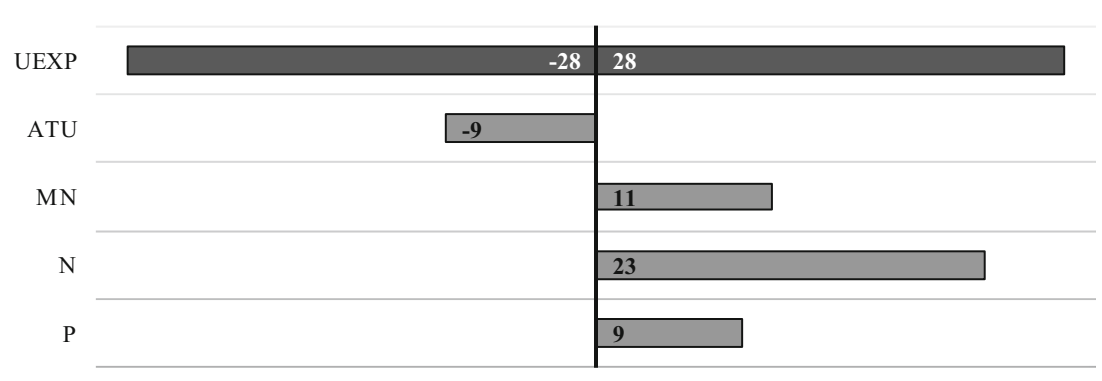

$\mathrm{rE} \%$ 
Fig. 3 Results of the batch tests at initial MET concentration of $50 \mathrm{ng} / \mathrm{L}$. Time profiles of a MET and COD removal efficiency and b ammonia, nitrate and nitrite concentrations (error bars indicate the standard deviation)
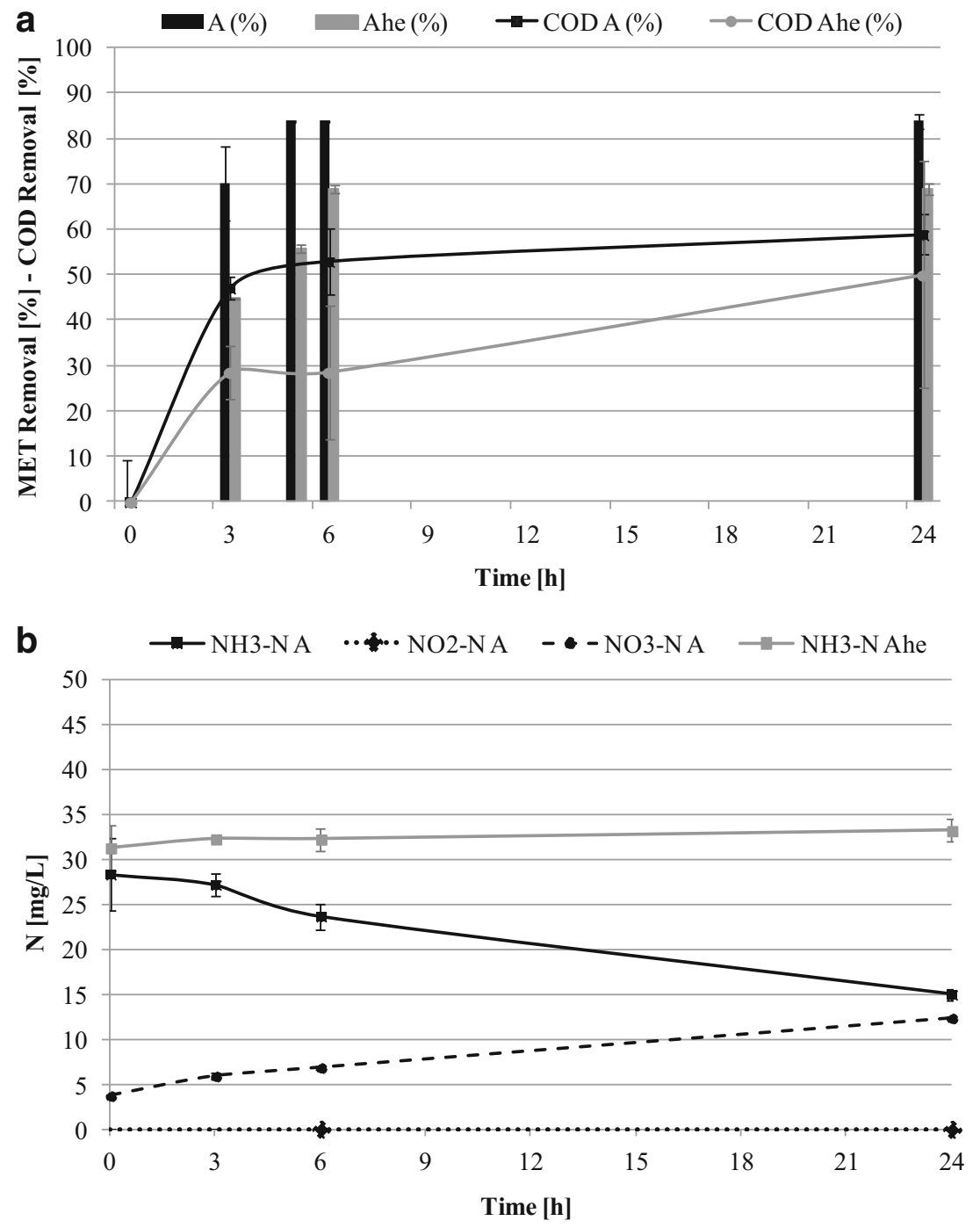

$I \mathrm{~N} \%=[1-($ SOURT-SOURhe $) /($ SOURTB-SOURheB $)] \cdot 100 \%$

- Zero-order

$C(t)=C_{0}-k_{0} \cdot t$

where SOUR and $\mathrm{SOUR}_{\mathrm{B}}$ indicate the specific respiration rates in each of the tested conditions and in the corresponding blank test, respectively.

\section{Kinetic models}

The experimental data collected from Series A were fitted considering the zero-, first-, pseudo first-, second-, and pseudo second-order kinetic models. The linear form of each equation, as reported below, was used to find out the best fitting model. For instance, the model providing the higher value of the correlation coefficient, $R^{2}$, between experimental and modelled data, was considered as the best fitting one.

The values of the kinetic constants were calculated based on the amount of MET removed from the liquid phase during Series A. The following equations were used to this purpose: $\ln C(t)=\ln C_{0}-k_{1} \cdot t$

- Second-order

$\frac{1}{C(t)}=\frac{1}{C_{0}}+k_{2} \cdot t$ 
Fig. 4 Results of the batch tests at initial MET concentration of $100 \mathrm{ng} / \mathrm{L}$. Time profiles of a MET and COD removal efficiency and b ammonia, nitrate and nitrite concentrations (error bars indicate the standard deviation)
- Pseudo-first order

$\ln \left(q_{\mathrm{e}}-q(t)\right)=\ln q_{\mathrm{e}}-k^{\prime}{ }_{1} \cdot t$

- Pseudo-second order

$\frac{t}{q(t)}=\frac{1}{k_{2}^{\prime} \cdot q_{\mathrm{e}}^{2}}+\frac{1}{q_{\mathrm{e}}} \cdot t$

where

$q_{\mathrm{e}}=\frac{M_{\mathrm{ads}}(e)}{\mathrm{MLSS}}=\frac{\left(C_{0}-C_{\mathrm{e}}\right)}{\mathrm{MLSS}}$ a
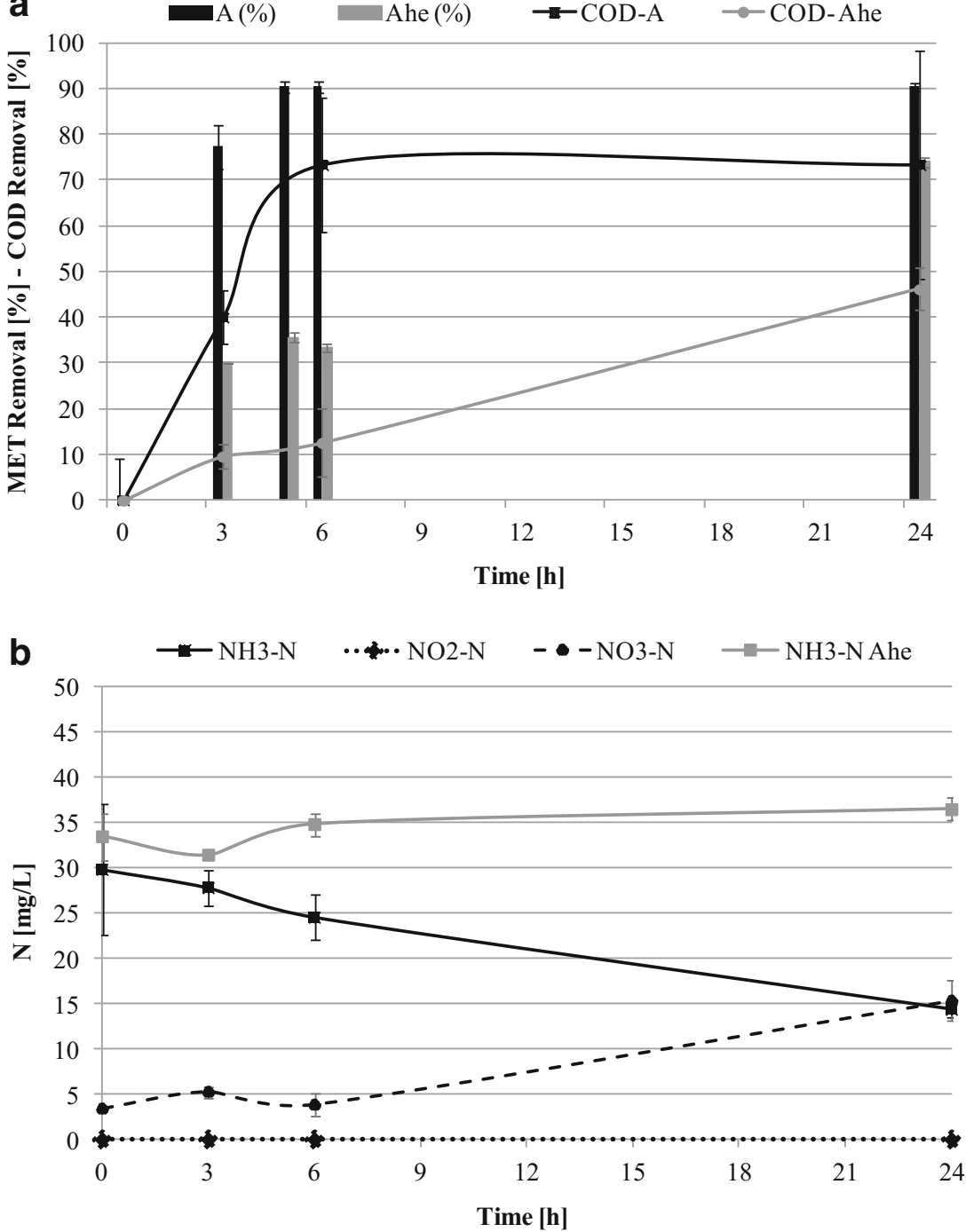

$q(t)=\frac{M_{\mathrm{ads}}(t)}{\operatorname{MLSS}}=\frac{\left(C_{0}-C(t)\right)}{\operatorname{MLSS}}$

In the above equations, $C_{0}$ and $C(t)$ indicate MET concentrations in the liquid phase at the beginning and at any time $\mathrm{t}$ of the test, respectively; $k_{0}, k_{1}, k_{2}, k_{1}^{\prime}$, and $k_{2}^{\prime}$ represent the rate constants of the zero-, first-, second-, pseudo first-, and pseudo second-order models, respectively; $q_{\mathrm{e}}$ and $q(t)$ stand for the amount of drugs per unit mass of adsorbent (i.e., sludge solids) at the equilibrium time and at any time $t$, respectively.

In Eqs. (18) and (19), $M_{\mathrm{ads}}(\mathrm{e})$ and $M_{\mathrm{ads}}(\mathrm{t})$ represent the mass of MET adsorbed on the sludge at equilibrium time and at any time $\mathrm{t}$ before, respectively, during the tests. Measurements of solid concentration at the beginning and at the end of each contact time showed that microbial growth during the tests was negligible. Therefore, the MLSS concentration in Eqs. (18) and (19) was considered equal to the average concentration measured throughout the tests. 
Fig. 5 Results of the batch tests at initial MET concentration of $200 \mathrm{ng} / \mathrm{L}$. Time profiles of a MET and COD removal efficiency and b ammonia, nitrate and nitrite concentrations (error bars indicate the standard deviation)
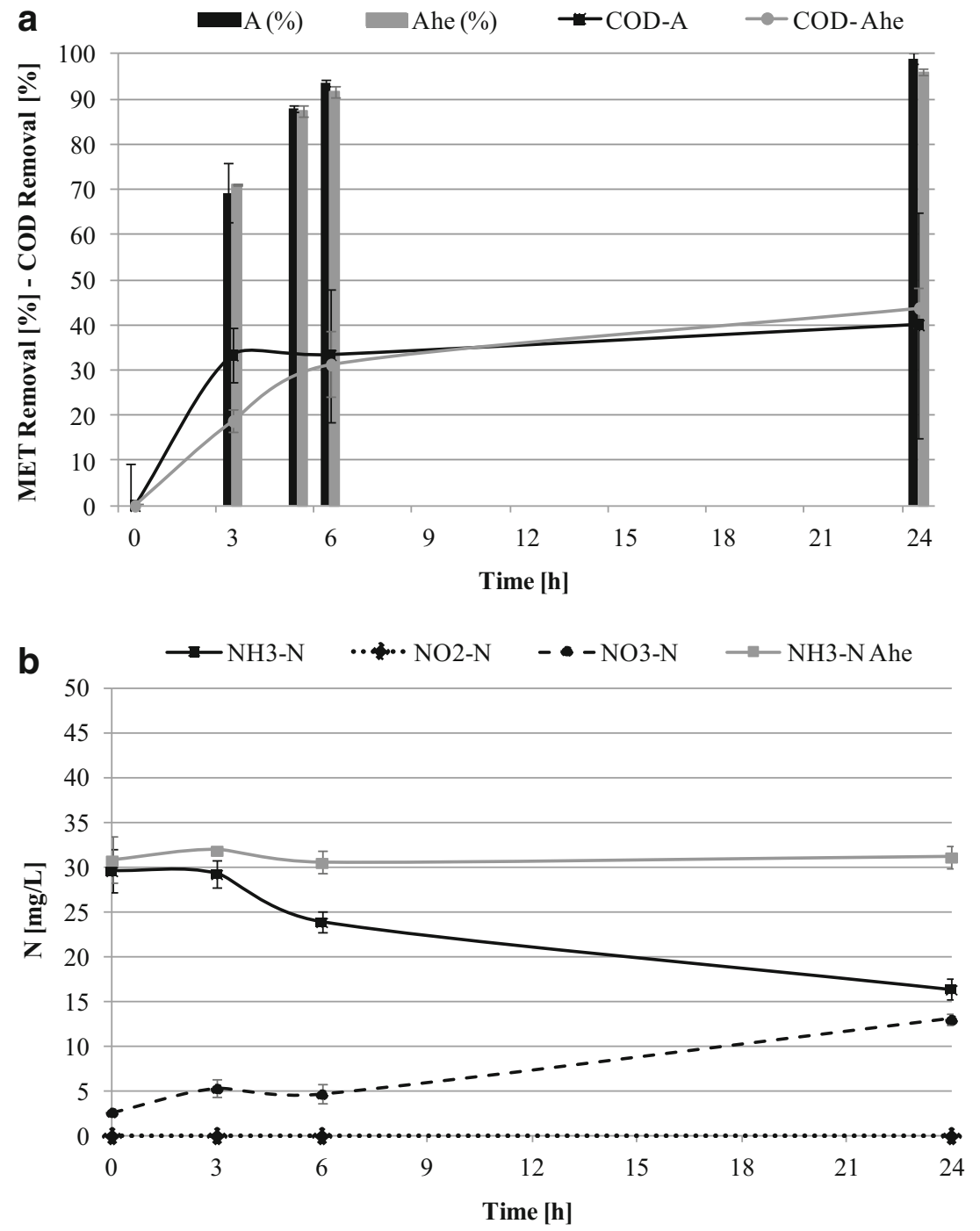

Fig. 6 Time profiles of SOUR in the biological tests and in the blank tests (error bars indicate the standard deviation)

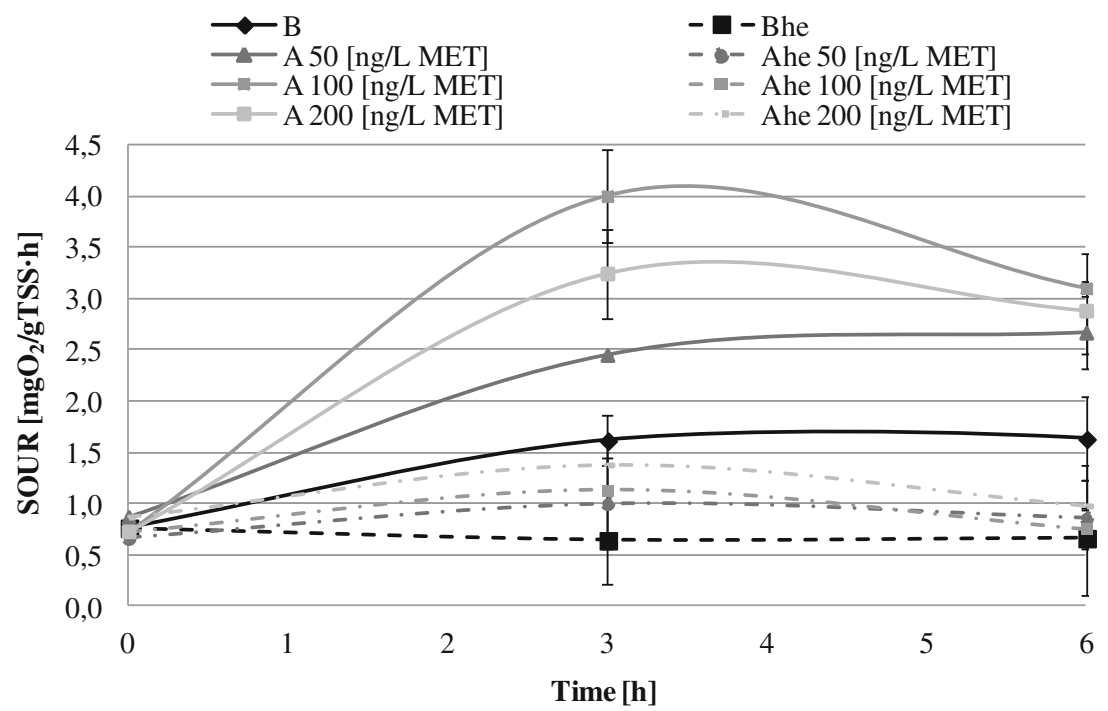


Table 3 Average results of removal efficiency measured in the biological tests at different MET initial concentration

\begin{tabular}{llllll}
\hline$C_{0}$ & $T$ & $\mathrm{RB}_{\mathrm{T}}$ & $\mathrm{RB}_{\mathrm{H}}$ & $\mathrm{RA}$ & $\mathrm{RO}$ \\
\hline$(\mathrm{ng} / \mathrm{L})$ & $(\%)$ & & & & \\
50 & 84 & 81 & 66 & 0 & 3 \\
100 & 90 & 86 & 70 & 3 & 2 \\
200 & 96 & 96 & 94 & 0 & 0 \\
\hline
\end{tabular}

$T$ total, $R B_{T}$ removal for biodegradation, $R B_{H}$ removal for heterotrophic biodegradation, $R A$ removal for adsorption, $R O$ removal for other abiotic processes

\section{Results and discussion}

\section{Analytical method optimization and validation}

The second transition of MET was chosen for the quantitative determination due to the best result of statistical parameters of the analytical method, as shown in Table 2 in terms of calibration curves linearity (MET-1 $R^{2}=0.9997$; MET-2 $R^{2}=$ 0.9999). Other results of the method validation are also reported in Table 2. Figure 1 shows two chromatograms representing the detection of MET in the standard solution used for calibration and in a sample collected from one of the overall biological process tests. It is possible to notice how the two chromatograms are perfectly comparable and that the effects of the complex matrix in sample (b) do not increase consistently the base noise.

Based on these results, shown in Table 2, it was considered to be addressing the objective of the study, i.e., to assess an analytical method for MET determination in the liquid and solid phase of a WWTP to be repeatable and reliable (recovery $>75 \%$, repeatability $<10-15 \%$, bias uncertainty $<30 \%$ ) and relatively easy to use, and therefore suitable for measurements on routine base.

\section{Matrix effect tests}

In order to evaluate the effect of the matrix components on MET determination, the Fisher's extract test was conducted. The results of this test are as follows:

$$
F_{\text {calc }}=4.08
$$

and

$F_{3,3}=9.27$ (Sokal and Rohlf 2009)

so $F_{\text {calc }} \leq F_{3,3}$

This result allows to confirm that the variances were statistically equivalents, so the matrix effects are statistically not relevant.

Furthermore, it is useful to observe the results of two replicates of MET concentration measured in the matrix effect tests for the different solutions, as shown in Fig. 2. The results are reported as relative error ( $\mathrm{rE} \%$ ) compared to the expected concentration (nominal concentration, $\mathrm{Cn}$, equal to $50 \mathrm{ng} / \mathrm{L}$ ). In the same figure, the expanded uncertainty of the analytical method is also reported. It is possible to note that the deviation (bias) measured in the different analysed matrices is included in the uncertainty of the method and that the measured values are statistically distributed around the true value (bias $=0$ ).

Therefore, it can be concluded that the adopted method for the analytical determination of MET is not statistically affected by the interaction with the tested wastewater components. The method results to be reliable and suitable for carrying measurements in the WWTPs. However, further tests on other matrices are needed as confirmation.

\section{Batch experiments}

Figures 3a, 4a, and 5a show removal efficiency of MET and the corresponding COD profiles in the absence (A) and in the presence of nitrification inhibition $\left(A_{\text {he }}\right)$ (i.e., measured during the overall biological and heterotrophic batch tests, respectively) conducted at 50, 100, and $200 \mathrm{ng} / \mathrm{L}$ MET. The figures show also the standard deviation calculated on the removal efficiency values of two replicates.

Figures 3b, 4b, and 5b show ammonia, nitrate, and nitrite nitrogen concentrations, respectively, versus time during the same tests.

MET profiles indicate that the drug is removed progressively during the tests. The highest reduction is occurring in the first 3-4 h, while afterwards removal becomes much

Table 4 Kinetics models and parameters of the overall biological process tests at different MET initial concentration (in italics the best fitting)

\begin{tabular}{|c|c|c|c|c|c|c|c|c|c|c|c|c|c|c|c|}
\hline$C_{0}(n g / L)$ & 50 & & & & & 100 & & & & & 200 & & & & \\
\hline$T_{e}(h)$ & 5 & & & & & 5 & & & & & 6 & & & & \\
\hline$C_{e}(n g / L)$ & $<$ LOQ & & & & & $<\mathrm{LOQ}$ & & & & & $<\mathrm{LOQ}$ & & & & \\
\hline \multirow[t]{2}{*}{ Kinetic order } & \multirow[t]{2}{*}{0} & \multirow[t]{2}{*}{ I } & \multirow[t]{2}{*}{ II } & \multicolumn{2}{|c|}{ Pseudo } & 0 & I & II & \multicolumn{2}{|c|}{ Pseudo } & 0 & I & II & \multicolumn{2}{|c|}{ Pseudo } \\
\hline & & & & $I$ & II & & & & $I$ & II & & & & $I$ & II \\
\hline$R^{2}$ & 0.24 & 0.25 & 0.23 & 1.00 & 0.12 & 0.28 & 0.47 & 0.74 & 0.99 & 0.44 & 0.36 & 0.84 & 0.98 & 0.99 & 0.40 \\
\hline Kinetic constant & $\begin{array}{l}0.86 \\
(\mathrm{ng} / \mathrm{L} \mathrm{h})\end{array}$ & $\begin{array}{l}0.04 \\
(1 / \mathrm{h})\end{array}$ & $\begin{array}{l}0.00 \\
(\mathrm{~L} / \mathrm{h} \mathrm{ng})\end{array}$ & $\begin{array}{l}0.66 \\
(1 / h)\end{array}$ & $\begin{array}{l}0.00 \\
(1 / \mathrm{h})\end{array}$ & $\begin{array}{l}1.66 \\
\text { (ng/L h) }\end{array}$ & $\begin{array}{l}0.07 \\
(1 / \mathrm{h})\end{array}$ & $\begin{array}{l}0.00 \\
(\mathrm{~L} / \mathrm{h} \mathrm{ng})\end{array}$ & $\begin{array}{l}0.58 \\
(1 / h)\end{array}$ & $\begin{array}{l}0.00 \\
(1 / \mathrm{h})\end{array}$ & $\begin{array}{l}3.24 \\
(\mathrm{ng} / \mathrm{L} \mathrm{h})\end{array}$ & $\begin{array}{l}0.16 \\
(1 / \mathrm{h})\end{array}$ & $\begin{array}{l}0.03 \\
(\mathrm{~L} / \mathrm{h} \mathrm{ng})\end{array}$ & $\begin{array}{l}0.47 \\
(1 / h)\end{array}$ & $\begin{array}{l}0.00 \\
(1 / \mathrm{h})\end{array}$ \\
\hline
\end{tabular}


lower. COD time-profiles follow very closely MET pattern, with the main removal also observed in the first $3-4 \mathrm{~h}$ of the tests. The behaviour of MET and COD remain basically the same at all the tested drug concentrations, and the removal efficiency increases as the concentration rises.

Comparison of the processes in the absence (A) and presence of nitrification inhibition $\left(A_{\text {he }}\right)$ shows higher values of removal in the former case, i.e., in the presence of both carbon and ammonia oxidation. This pattern is observed at all the tested concentrations, and particularly at 50 and $100 \mathrm{ng} / \mathrm{L}$ of MET.

Measurements of ammonia during the overall biological tests show its continuous conversion into nitrate, as reported in Figs. 3b, 4b, and 5b: nitrification in the presence of MET proceeds regularly with no significant difference with respect to the processes observed in the blank tests (reported as supplementary material). Nitrite production is very low in all the cases, thus indicating complete nitrification into nitrate. Therefore, it can be concluded that nitrifying bacteria provide a contribution to the removal of MET, whereas nitrification is not negatively affected by the presence of the drug. It is noteworthy that MET is a nitrogenous compound; therefore, the presence of MET in the mixed liquor might be able to stimulate autotrophic biomass activity, without compromising other reactions such as observed in a previous study by Chiavola et al. (2017).

Figure 6 shows the corresponding SOUR values determined at time $t=0,3$ and $6 \mathrm{~h}$, where the first value refers to the endogenous respiration SOUR. The same figure also displays the SOUR measured in the blank tests (i.e., in the absence of MET). It can be noted that at all the tested drug concentrations, SOUR is always higher when MET is present: it seems that the drug is capable of stimulating the biological activity, although its concentration remains significantly lower than COD and ammonia. Based on the respiration inhibition tests procedure, it can be assessed that inhibition effects are completely absents either on heterotrophic or autotrophic biomass activity. Therefore, the percentage inhibition indices reported in Eqs. (10), (11), and (12) cannot be calculated.

Since the tested concentrations of MET fall within the typical values found in the influent to WWTPs, the results here obtained indicate that the presence of this drug does not negatively affect the biological activity in the reactor. Furthermore, within the 6-h contact time and at a concentration of activated sludge which is similar to the average found in the WWTPs, almost complete removal of MET is achieved even starting from the highest value, i.e. $200 \mathrm{ng} / \mathrm{L}$ of MET. This is in a good agreement with the work of Baker and Kasprzyk-Hordern (2013) and the review of Nefau et al. (2013) where a total removal and a removal from 50 to $100 \%$ of MET in activated sludge treatment plants was reported, respectively.
Table 3 reports average removal efficiency measured in the batch tests, where $T$ stands for the total removal, while $\mathrm{RB}_{\mathrm{T}}$ and $\mathrm{RB}_{\mathrm{H}}$ refer to the values ascribed to the biological processes, either overall or only heterotrophic, respectively, calculated after reduction of the contribution due to adsorption (RA) and to other abiotic processes (RO) (as outlined in Eqs. (6), (7), (8), and (9)). As outlined above, the total removal improves at increasing MET concentrations, from 84 to $96 \%$ at 50 and $200 \mathrm{ng} / \mathrm{L}$, respectively. Contributions of adsorption and other abiotic processes are always negligible, as highlighted by Bagnall et al. (2013) and the main removal can be ascribed to the biological activity. These results agree with the high solubility and the hydrophilic characteristics of $\operatorname{MET}\left(K_{\mathrm{OW}}=2.95, S=1.33 \times 10^{4}\right)$, as reported in Table 1 . Furthermore, concentrations detected in the solid phase were always lower than LOQ (2.4 ngMET/gTSS) either at the beginning or at the end of the tests. Thus, it is confirmed the reduced tendency of the contaminant to be adsorbed, according to the values found for $\log \mathrm{K}_{\mathrm{OC}}$ and $\log \mathrm{K}_{\mathrm{OW}}$.

The results obtained by the application of the selected kinetic models to the data from the overall biological processes are summarized in Table 4 . The same table shows the equilibrium time, $T_{\mathrm{e}}$, and the corresponding MET concentration, $C_{\mathrm{e}}$. It is possible to observe that the experimental data fit better the pseudo first-order kinetic model for all the tested concentrations of MET (highlighted in bold). The values of $C_{e}$ are always below the detection limit, thus indicating complete removal, whereas the equilibrium time does not change significantly with concentration.

\section{Conclusions}

The aim of the present study was to provide a better knowledge of the fate of MET in the WWTPs for domestic sewage. Furthermore, in order to make detection of MET in the complex matrices of wastewater and sludge more reliable, a detailed study was conducted by investigating the effects of the macro-components of wastewater on the analytical determination.

Batch tests highlighted that MET concentrations in the range $50-200 \mathrm{ng} / \mathrm{L}$ can be completely removed in the oxidation reactor, with the process to be mainly ascribed to the biological activity of both heterotrophic and autotrophic bacteria. Furthermore, the respirometric tests showed that MET does not induce any inhibition; by contrast, being a nitrogenous compound, it might favour the nitrifying bacteria activity. Adsorption of MET onto activated sludge solids was always very low; therefore, from a MET contamination point of view, reuse of excess sludge, as usually adopted in the WWTPs for final disposal, does not represent a source of negative impact on the environment. 
Batch tests will be repeated using real wastewater to confirm the results here obtained.

Matrix effect tests highlighted that the main components of wastewater affect detection of MET for about 9-23\%, which is comparable with the uncertainties of the analytical method (about $\pm 28 \%$ ). Therefore, the adopted method can be considered reliable and can be used on routine basis for MET determinations in wastewater.

\section{References}

APHA (2005) Standard methods for the examination of water and wastewater, 21st edn. American Public Health Association/American Water Works Association/Water Environment Federation, Washington DC

Andersen HR, Hansen M, Kjølholt J, Stuer-Lauridsen F, Ternes T, Halling-Sørensen B (2005) Assessment of the importance of sorption for steroid estrogens removal during activated sludge treatment. Chemosphere 61(1):139-146. https://doi.org/10.1016/j. chemosphere.2005.02.088

Andrés-Costa MJ, Andreu V, Picó Y (2017) Liquid chromatographymass spectrometry as a tool for wastewater-based epidemiology: assessing new psychoactive substances and other human biomarkers. TrAC. Trends Anal Chem 94:21-38. https://doi.org/10. 1016/j.trac.2017.06.012

Bagnall JP, Evans SE, Wort MT, Lubben AT, Kasprzyk-Hordern B (2012) Using chiral liquid chromatography quadrupole time-of-flight mass spectrometry for the analysis of pharmaceuticals and illicit drugs in surface and wastewater at the enantiomeric level. J Chromatogr A 1249:115-129. https://doi.org/10.1016/j.chroma.2012.06.012

Bagnall JP, Malia L, Lubben A, Kasprzyk-hordern B (2013) Stereoselective biodegradation of amphetamine and methamphetamine in river microcosms. Water Res 47(15):5708-5718. https:// doi.org/10.1016/j.watres.2013.06.057

Baker DR, Kasprzyk-Hordern B (2013) Spatial and temporal occurrence of pharmaceuticals and illicit drugs in the aqueous environment and during wastewater treatment: new developments. Sci Total Environ 454-455:442-456. https://doi.org/10.1016/j.scitotenv.2013.03.043

Baker DR, Kasprzyk-Hordern B (2011) Multi-residue analysis of drugs of abuse in wastewater and surface water by solid-phase extraction and liquid chromatography-positive electrospray ionisation tandem mass spectrometry. J Chromatogr A 1218(12):1620-1631. https:// doi.org/10.1016/j.chroma.2011.01.060

Bodík I, Mackul'ak T, Fáberová M, Ivanová L (2016) Occurrence of illicit drugs and selected pharmaceuticals in Slovak municipal wastewater. Environ Sci Pollut Res 23(20):21098-21105. https://doi.org/10. 1007/s11356-016-7415-5

Boix C, Ibáñez M, Sancho JV, Rambla J, Aranda JL, Ballester S, Hernández F (2015) Fast determination of 40 drugs in water using large volume direct injection liquid chromatography-tandem mass spectrometry. Talanta 131:719-727. https://doi.org/10.1016/j. talanta.2014.08.005

Castiglioni S, Bijlsma L, Covaci A, et al (2016) Estimating community drug use through wastewater-based epidemiology. Assessing illicit drugs in wastewater: advances in wastewater-based drug epidemiology, EMCDDA Insights 22:17-33, Publications Office of the European Union, Luxembourg. doi:https://doi.org/10.2810/017397
Castiglioni S, Thomas KV, Kasprzyk-Hordern B, Vandam L, Griffiths P (2014) Testing wastewater to detect illicit drugs: state of the art, potential and research needs. Sci Total Environ 487:613-620. https://doi.org/10.1016/j.scitotenv.2013.10.034

Chiavola A, Tedesco P, Boni MR (2017) Fate of selected drugs in the wastewater treatment plants (WWTPs) for domestic sewage. Environ Sci Pollut Res:1-11. https://doi.org/10.1007/s11356-0179313-x

Deblonde T, Cossu-Leguille C, Hartemann P (2011) Emerging pollutants in wastewater: a review of the literature. Int J Hyg Environ Health 214(6):442-448. https://doi.org/10.1016/j.ijheh.2011.08.002

Devault DA, Néfau T, Levi Y, Karolak S (2016) The removal of illicit drugs and morphine in two waste water treatment plants (WWTPs) under tropical conditions. Environ Sci Pollut Res 24(33):1-11. https://doi.org/10.1007/s11356-015-6032-z

Díaz-Cruz MS, García-Galán MJ, Guerra P, Jelic A, Postigo C, Eljarrat E, Farré M, López de Alda MJ, Petrovic M, Barceló D (2009) Analysis of selected emerging contaminants in sewage sludge. TrAC - Trends Anal Chem 28(11):1263-1275. https://doi.org/10.1016/j.trac.2009. 09.003

European Monitoring Centre for Drugs and Drug Addiction (2017), European drug report 2017: trends and developments, Publications Office of the European Union, Luxembourg doi:https://doi.org/10. 2810/610791

Gerrity D, Trenholm RA, Snyder SA (2011) Temporal variability of pharmaceuticals and illicit drugs in wastewater and the effects of a major sporting event. Water Res 45(17):5399-5411. https://doi.org/10. 1016/j.watres.2011.07.020

Gómez MJ, Herrera S, Solé D, García-Calvo E, Fernández-Alba AR (2012) Spatio-temporal evaluation of organic contaminants and their transformation products along a river basin affected by urban, agricultural and industrial pollution. Sci Total Environ 420:134-145. https://doi.org/10.1016/j.scitotenv.2012.01.029

Irvine RJ, Kostakis C, Felgate PD, Jaehne EJ, Chen C, White JM (2011) Population drug use in Australia: a wastewater analysis. Forensic Sci Int 210(1-3):69-73. https://doi.org/10.1016/j.forsciint.2011.01.037

Nefau T, Karolak S, Castillo L, Boireau V, Levi Y (2013) Presence of illicit drugs and metabolites in influents and effluents of 25 sewage water treatment plants and map of drug consumption in France. Sci Total Environ 461-462:712-722. https://doi.org/10.1016/j. scitotenv.2013.05.038

OECD (2010) Test No. 209: Activated Sludge, Respiration Inhibition Test. OECD Guidel Test Chem Sect 2 Eff Biot Syst 209:1-18. doi: https://doi.org/10.1787/9789264070080-en

Pal R, Megharaj M, Kirkbride KP, Naidu R (2015) Adsorption and desorption characteristics of methamphetamine, 3,4methylenedioxymethamphetamine, and pseudoephedrine in soils. Environ Sci Pollut Res 22(12):8855-8865. https://doi.org/10.1007/ s11356-014-2940-6

Sokal RR, Rohlf FJ (2009) Introduction to biostatistics second edition. Dover Publications Inc, NY 1081:1-590. https://doi.org/10.1017/ CBO9780511608117.001

Vilardi G, Verdone N, Di Palma L (2017) The influence of nitrate on the reduction of hexavalent chromium by zero-valent iron nanoparticles in polluted wastewater. Desalin Water Treat 20710:20710-20258. https://doi.org/10.5004/dwt.2017.20710

Ying Z, Droste RL (2015) Sorption of microconstituents onto primary sludge. Water Sci Technol 72(5):779-784. https://doi.org/10.2166/ wst. 2015.270 